\title{
Der europäische Stadtarzt: Internationales Seminar über Stadt- und Staatsärzte vor 1800 (17.-19. September 1979 in Wolfenbüttel)
}

Bericht von Huldrych M. Koelbing

Die Herzog-August-Bibliothek in Wolfenbüttel bei Braunschweig - ihr berühmtester Bibliothekar war Lessing - enthält nicht nur eine einzigartige Sammlung von Literatur aus der frühen Neuzeit und über diese; sie ist auch ein gastfreier Ort für das wissenschaftliche Gespräch. Dem Leiter des Forschungsprogrammes, Prof.Dr.phil. Walter Killy - man pflegt ihn den «Resident Fellow » zu nennen -, ist es zu danken, daß nun auch die Society for the Social History of Medicine aus London die großzügige Wolfenbütteler Gastfreundschaft in Anspruch nehmen durfte. "The town and state physician in Europe from the Middle Ages to the Enlightenment» - so war die Thematik umschrieben, die hier drei Tage lang von verschiedenen Seiten beleuchtet und diskutiert wurde. Ein Kreis von zwei Dutzend Teilnehmern, acht Vorträge und reichlich Zeit zur Erörterung des Gebotenen - es waren ideale Voraussetzungen für eine fruchtbare Tagung.

Sie begann gleich auf höchstem wissenschaftlichem und rhetorischem Niveau: Herr Vivian Nutton (London) stellte souverän zusammen, was man über das Amt der Stadtärzte in der Antike zuverlässig weiß, und zeichnete so den Hintergrund für die späteren Entwicklungen. Die Legende von einem perikleischen Gesundheitsdienst mit unentgeltlicher ärztlicher Behandlung für sämtliche Athener löste sich dabei in nichts auf. Auch in hellenistischer und römischer Zeit hatte die Bestallung eines Stadtarztes zur Hauptsache den Sinn, dem Gemeinwesen die ständige Anwesenheit eines tüchtigen Arztes zu sichern. (Es konnten auch mehrere sein.) Die antike Tradition lebte im 13. Jahrhundert in Italien wieder auf, indem die Rechtsgelehrten von Bologna die Aufmerksamkeit ihrer Studenten auf die römische Institution des öffentlich besoldeten Arztes lenkten; die angehenden Administratoren unter den Hörern setzten später diese Anregung in Wirklichkeit um.

Richard Palmer (London) verfolgte die Entwicklung des Amtes der italienischen Stadtärzte, der «medici condotti», weiter. Solche Verträge mit oft fremden Ärzten wurden nur so lange abgeschlossen, als man nicht über genügend eigene Leute verfügte. Vom 16. Jahrhundert an verfolgten die örtlichen Collegia medica eine auf Ausschluß fremder Kollegen resp. Konkurrenten gerichtete Bewilligungspolitik. Sie übernahmen mehr und mehr auch Funktionen im Dienste des Staates, wie die Überwachung der Medizinalpersonen. Die energischen Bemühungen der 
italienischen Städte zur Abwehr der Pest führten im 15./16. Jahrhundert im ganzen Land zur Einsetzung von städtischen Sanitätsräten, die vorwiegend aus Männern der Politik und der Verwaltung bestanden.

Frau Ghada Karmi, die London demnächst mit einer Professur in Jordanien vertauschen wird, unterrichtete uns über das mittelalterlich-islamische Modell der Organisation und Kontrolle ärztlicher Dienste. Der Herrscher schrieb u.a. ärztliche Prüfungen vor; über die Einhaltung berufsethischer Normen wachte in den Städten der vom Kalifen eingesetzte «Muhtasib», eigentlich der Marktaufseher. Hier wie anderswo läßt sich leider rückblickend oft nicht feststellen, in welchem Ausmaß die erlassenen Vorschriften tatsächlich eingehalten wurden. Dieser Gegensatz zwischen Theorie und Praxis, Konzept und Wirklichkeit kam während der ganzen Konferenz immer wieder zur Sprache.

Die Vielfalt der Heilberufe im Spanien des 16. Jahrhunderts und die verschiedenen Varianten städtischer, ständischer und königlicher Einflußnahme auf das Medizinalwesen legte José Maria López Piñero (Valencia) dar. Islamische Einflüsse auf spanische Institutionen, spanische Wirkungen auf Italien wurden erkennbar; namentlich ist es die kontrollmächtige Funktion des Protomedicus im Königreich Sizilien, deren Entstehung (1397) auf spanisches Vorbild zurückzugehen scheint.

Toby Gelfand (Ottawa) hat aus französischen Archivquellen unbekannte Dinge über staatliche Medizin und «medical careers» zur Zeit Ludwig des XV. zutage gefördert. Neben dem Einsatz von Ärzten durch den Staat bei Epidemien beschränkten sich die öffentlichen Maßnahmen zu jener Zeit im wesentlichen auf den Versand von Arzneisortimenten, «boîtes de remèdes», in die Provinzen. Im Bereich der privaten Initiative konnte Gelfand nachweisen, wie besonders in den weiten ländlichen Gebieten der Gascogne relativ viele junge Männer danach drängten, sich am Collège de chirurgie in Paris zu Wundärzten auszubilden und sich so eine freiere Stellung im Leben zu erringen, als es die Bindung an die Scholle daheim erlaubte.

In das südöstliche Grenzgebiet des christlichen Europa führte der Vortrag von Norbert Duka Zólyomi (Preßburg) über «Die Entwicklung amtsärztlicher Institutionen im historischen Ungarn». Hier gaben lange Zeit nur Pestepidemien Anlaß zur Einstellung von Ärzten durch die Städte. Die Behandlung der Armen, im deutschen Sprachgebiet ein Hauptmotiv für die Schaffung von Stadtarztstellen, blieb im Königreich Ungarn lange eine Nebensache.

Die Vielfalt der Sachverhalte, die sich hinter der Etikette «Stadtarzt» oder «Physicus» verbirgt und jede Generalisierung in der Charakterisierung des Amtes verbietet, wurde von Manfred Stürzbecher (Berlin) anhand der deutschen Ver- 
hältnisse mit Nachdruck hervorgehoben. Huldrych M. Koelbing (Zürich) wies auf große Unterschiede schon in der kleinen Schweiz hin. Beispielsweise hebt sich das im 16./17. Jahrhundert ausgebaute, differenzierte öffentliche Medizinalwesen Zürichs nicht unvorteilhaft von den Verhältnissen in Basel ab, wo der einzige Stadtarzt im Schatten der Medizinischen Fakultät stand und nicht selten von ihr angefeindet seine Bürde als Arzt, Epidemiologe und Gerichtsmediziner tragen mußte. Originell und weitblickend war die zürcherische Einrichtung der «Medici stipendiati», die schon in gesunden Zeiten besoldet wurden, um bei ausbrechenden Epidemien Dienst zu tun. Die Zustände in England wurden wenigstens in der Diskussion von den Herren William Bynum (London) und Vivian Nutton besprochen: Im 17. Jahrhundert verdrängte das Vertrauen in die lebendige individuelle Hilfsbereitschaft der Ärzte insgesamt den Stadtarzt als Armenarzt.

Ärzte sollten für alle Leute erreichbar sein, und sie sollten bei tödlichen Epidemien auf ihren Posten bleiben. Hiefür und gleichzeitig, um Experten zur Überwachung der anderen Medizinalpersonen, zur Seuchenbekämpfung und zur Beurteilung von Delikten gegen Leib und Leben zur Hand zu haben, stellten die europäischen Städte der frühen Neuzeit zu ganz unterschiedlichen Bedingungen nebenamtliche Stadtärzte ein. Eine üppige, zugleich aber verwirrende Vielfalt der Ausdruck drängt sich erneut auf - kennzeichnet die Intentionen und ihre Verwirklichung. Das wurde an diesem Seminar deutlich. Die Organisatoren der Tagung, Herr Robin Price in London als Sekretär der Society for the Social History of Medicine und Frau Sabine Solf als Gastgeberin in Wolfenbüttel, verdienen den uneingeschränkten Dank aller Seminarteilnehmer - und der künftigen Leser des nun in Druck gehenden Verhandlungsberichtes.

Prof. Dr. med. Huldrych M. Koelbing

Medizinhistorisches Institut

Rämistraße 71

8006 Zürich 